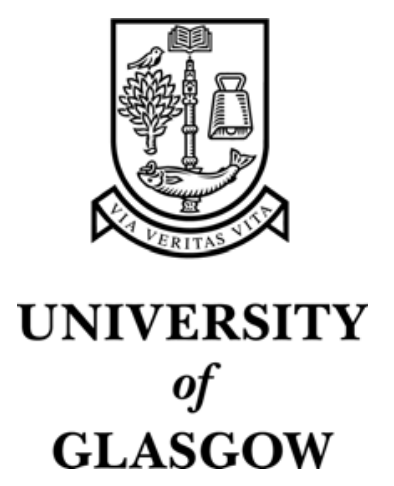

Hart, C.L. and Deary, I.J. and Davey Smith, G. and Upton, M.N. and Whalley, L.J. and Starr, J.M. and Hole, D.J. and Wilson, V. and Watt, G.C.M. (2005) Childhood IQ of parents related to characteristics of their offspring: linking the Scottish Mental Survey 1932 to the Midspan Family Study. Journal of Biosocial Science 37(5):pp. 623-639.

http://eprints.gla.ac.uk/3133/ 


\title{
CHILDHOOD IQ OF PARENTS RELATED TO CHARACTERISTICS OF THEIR OFFSPRING: LINKING THE SCOTTISH MENTAL SURVEY 1932 TO THE MIDSPAN FAMILY STUDY
}

\author{
C. L. HART*, I. J. DEARY†, G. DAVEY SMITH†, M. N. UPTON§, \\ L. J. WHALLEY $\mid$, J. M. STARR\|, D. J. HOLE*, V. WILSON** AND \\ G. C. M. WATT§
}

* Public Health and Health Policy, University of Glasgow, UK, $\dagger$ Psychology, University of Edinburgh, UK, \$Department of Social Medicine, University of Bristol, UK, $\S$ General Practice and Primary Care, University of Glasgow, UK, $\mid$ Department of Mental Health, University of Aberdeen, UK, \|Royal Victoria Hospital, Edinburgh, UK and **The Scottish Council for Research in Education Centre, University of Glasgow, UK

\begin{abstract}
Summary. The objective of the study was to investigate the relationship between childhood IQ of parents and characteristics of their adult offspring. It was a prospective family cohort study linked to a mental ability survey of the parents and set in Renfrew and Paisley in Scotland. Participants were 1921-born men and women who took part in the Scottish Mental Survey in 1932 and the Renfrew/Paisley study in the 1970s, and whose offspring took part in the Midspan Family study in 1996. There were 286 offspring from 179 families. Parental IQ was related to some, but not all characteristics of offspring. Greater parental IQ was associated with taller offspring. Parental IQ was inversely related to number of cigarettes smoked by offspring. Higher parental IQ was associated with better education, offspring social class and offspring deprivation category. There were no significant relationships between parental IQ and offspring systolic blood pressure, diastolic blood pressure, cholesterol, glucose, lung function, weight, body mass index, waist hip ratio, housing, alcohol consumption, marital status, car use and exercise. Structural equation modelling showed parental IQ associated with offspring education directly and mediated via parental social class. Offspring education was associated with offspring smoking and social class. The smoking finding may have implications for targeting of health education.
\end{abstract}

\section{Introduction}

Early life experiences, even those in utero (Barker, 1994), have been linked to health outcomes in adulthood (Elo \& Preston, 1992). Several studies have demonstrated links 
between parental social class - the socioeconomic environment during childhood and cardiovascular disease and mortality in adulthood. Poorer parental social class is associated with poorer cardiovascular health (Poulton et al., 2002) and premature mortality (Kuh et al., 2002), in particular from cardiovascular disease, respiratory disease, lung and stomach cancer (Davey Smith et al., 1998b). In addition to parental social class, parental area-of-residence deprivation category can be used as a measure of early life socioeconomic environment (Carstairs \& Morris, 1991). It is valuable to have both, as social class captures aspects of an occupational group and deprivation captures aspects of the area of residence. However, since there are different individuals in each social class group and at each level of deprivation, an individual parental measure may be of interest when investigating effects on the health of the next generation. In this study, the variable 'parental childhood IQ' is used. Childhood mental ability predicts a person's health and mortality many years later (Whalley \& Deary, 2001; Hart et al., 2003b). Since parents and offspring share both genes and environment, it is possible that some health outcomes in offspring may be related to parental mental ability.

Data from two sources were used: the Midspan Family study, which was a two-generational cardiorespiratory study of parents and offspring, and the Scottish Mental Survey of 1932 (SMS1932). The SMS1932 recorded mental ability in childhood of the parents in the Midspan Family study. At the time, they were all in compulsory education and aged between $10^{\frac{1}{2}}$ and $11^{\frac{1}{2}}$ years, so the measure was not a surrogate for educational level. It is unusual to have such information from two generations and, in this paper, parental childhood IQ is related to health and social characteristics of their offspring.

\section{Methods}

The SMS1932, conducted under the auspices of the Scottish Council for Research in Education (SCRE), was a mental ability test taken by nearly all children who were born in 1921 and attending school in Scotland on $1^{\text {st }}$ June 1932 (Scottish Council for Research in Education, 1933). The test was based on the Moray House Test number 12, which was used in 'eleven plus' examinations in England. It was taken by 87,498 children (44,210 boys and 43,288 girls) and validated by testing 500 boys and 500 girls on the Stanford-Binet test. The correlation between the two test results was 0.81 for boys and 0.78 for girls (Scottish Council for Research in Education, 1933).

The Midspan studies were a range of cardiorespiratory screening studies which took place in Scotland in the 1960s and 1970s. The Collaborative working population (Davey Smith et al., 1998a) and the Renfrew/Paisley general population (Hawthorne et al., 1995) studies contained people born in the year 1921, who may have taken part in the SMS1932 as children. Ethical permission was obtained from the Multi-Centre Research Ethics Committee for Scotland to link the SMS1932 data set with the 1921-born Midspan participants. Full details of the matching process were reported previously (Hart et al., 2003a), resulting in 938 (75\%) of the 1921-born Midspan participants being successfully linked to their mental ability test results from the SMS1932. Since the ages of the children ranged from $10 \frac{1}{2}$ to $11 \frac{1}{2}$ years, the test scores 
were corrected for age in days at the time of testing and converted to usual IQ-type scores with mean 100 and standard deviation 15 .

The Midspan family study was a prospective cohort study covering two generations: the Renfrew/Paisley study and their offspring. Between 1972 and 1976, all residents of the towns of Renfrew and Paisley who were then aged between 45 and 64 were invited to participate in a health screening study and nearly $80 \%$ took part: a total of 7052 men and 8354 women (Hawthorne et al., 1995). They completed a questionnaire on personal and health characteristics and attended a screening centre for a physical examination. Due to the geographical location of the study and the age ranges of the participants, there were 4064 married couples. In 1996, the second component of the family study took place (Upton et al., 2000). Survivors of the married couples were written to and asked if they had any children. In the case where both members were deceased, the informant on the death certificate was contacted for information on children. Offspring aged 30-59 years and living locally were identified (3202 offspring from 1767 families). The offspring were invited to complete a questionnaire and attend a screening examination, similar to their parents 20 years previously. In all, 1040 male and 1298 female offspring from 1477 families took part, a response rate of $73 \%$. There were 192 parents who took part in the SMS1932 and whose offspring took part in the family study. The parents included thirteen couples, resulting in 179 families with 286 offspring. For each of the thirteen couples where both parents had an IQ score available from the SMS1932, one parent was chosen at random, using SPSS random selection.

\section{Parental variables}

Parental variables included social class, deprivation category, height and smoking habit. Social class was derived from the occupation given on the questionnaire and classified in six groups with lower numbers representing the professional classes (General Register Office, 1966). Women were allocated their own social class, unless they reported being housewives, in which case they were allocated their husbands' social class. Deprivation category, as defined by Carstairs and Morris (Carstairs \& Morris, 1991), was obtained from the postcode of residence. Values were from one to seven, with higher numbers representing more deprived areas. Height was recorded without shoes at the screening examination and given here in millimetres. Number of cigarettes smoked per day was recorded on the questionnaire for current and former smokers.

\section{Offspring variables}

A similar questionnaire completed by the offspring included questions on occupation, from which social class was derived. Women's social class was based on their own occupation (Gunnell et al., 2003). Deprivation category was derived from the home address. Participants supplied their marital status, which was converted into married or other. Education was provided as: highest level completed (university, other professional/technical qualification or school), years of full-time education, number of Standard grades/'O' levels passed (examinations taken at age 15-16), 
number of Highers/'A' levels passed (examinations taken at age 17-18). The type of accommodation occupied was classified as owner-occupier or other and the number of rooms for the household's own use was recorded. The question on number of cars available to the household was converted to none or at least one. Smoking information was defined as ever-smoker (current or former) or never-smoker, and also as the number of cigarettes smoked per day for current and former smokers, with zero for never-smokers. The total units of alcohol consumed per week was obtained from questions on beer, spirits and wine (and similar drinks) consumed each day of the previous week. Exercise was obtained from answers to questions on usual daily activity and physical activity during non-working time. Participants who were not very, or not at all physically active during their usual daily activities and who were physically active outside work less than once a week or never, were classified as having no exercise.

At the screening examination, standing height and sitting height (seated on a stool) were measured without shoes in the Frankfort plane with a Holtain stadiometer to the nearest millimetre. Leg length was calculated as the difference between the standing and sitting height, with the height of the stool added. Trunk length was calculated as the difference between standing height and leg length. Weight was measured to the nearest $100 \mathrm{~g}$ wearing indoor clothes but no shoes. Body mass index was calculated as weight divided by standing height squared. The waist circumference was measured under clothing and the hip circumference measured over indoor clothing, enabling the waist-hip ratio to be calculated.

Forced expiratory volume in 1 second (FEV1) was measured with a Fleisch pneumotachograph that was connected to Spirotrac III software (Vitalograph UK). Percentage predicted FEV1 was defined as the actual FEV1 as a percentage of the expected FEV1. The expected FEV1 was calculated from sex-specific equations generated from linear regressions of age and height for a healthy subsample of the population:

Expected FEV1 $=-4.508-0.0229 \times$ age $+0.0534 \times$ height in $\mathrm{cm}$ (for males),

Expected FEV1 $=-1.474-0.0284 \times$ age $+0.0339 \times$ height in $\mathrm{cm}$ (for females).

A non-fasting venous blood sample was taken for measurement of total cholesterol and glucose. Blood pressure was taken with the subject seated, using an automated Dinamapp 8100 instrument. After five minutes rest, three blood pressure readings were taken and the means of the last two readings for systolic and diastolic pressure were used.

\section{Statistical methods}

Parental IQ was related to characteristics of offspring. Since there was one or more offspring per parent, models were used which accounted for any family effects. For continuous variables, the mixed procedure in SPSS version 11 was used. If the random effect for family was non-significant, then linear regression techniques were used instead. For discrete variables, the SAS macro GLIMMIX was used. Again, if there were no family effect, logistic regression was used instead. If any significant effect of parental IQ on a characteristic was found, further models using parental social class, parental deprivation category and parental height (in the case of offspring 
height) were built. For these analyses, the five people with missing parental social class were excluded. Age of the offspring at screening was included in models where it was significant. Interactions between IQ and social class or IQ and deprivation category were tested by adding interaction terms to the models. Analyses were repeated using mothers and fathers separately.

Structural Equation Modelling (SEM) allows a number of inter-related variables to be configured as a hypothesized network of associations. A hypothetical model of the associations among parental IQ, social class and deprivation category, and offspring years of education, social class, deprivation category and smoking was tested with SEM using the EQS program (Bentler, 1995). The hypotheses used to guide the construction of the model were highly constrained by the timing of the variables. Parental IQ was tested at age 11 in 1932; therefore, this was assumed to influence parental social class and deprivation category, which were measured at middle age, in the 1970s. Offspring social class, deprivation category and smoking referred to information from the 1990s and were therefore the outcome variables. Offspring years of education referred to a period prior to these outcomes and it was hypothesized to mediate between parental and offspring social variables. The maximum likelihood technique was used. Chi squared, residual covariance and fit indices were used to indicate goodness-of-fit of the model to the data. The procedure provides parameter weights that indicate the strength of association between variables in the model. For this part of the analysis, the model was constructed with one offspring per family using SPSS random selection, providing 179 cases, and 175 with non-missing data were used.

\section{Results}

There were 179 1921-born parents (92 male and 87 female) with 286 offspring (128 male and 158 female) in the study. There were 108 parents with one offspring screened, 48 with two offspring, fourteen with three, six with four, two with five and one parent with six offspring screened. The 92 fathers had 137 offspring (69 male and 68 female) and the 87 mothers had 149 offspring (59 male and 90 female).

The results of models showed no significant relationships between parental IQ and offspring systolic blood pressure, diastolic blood pressure, cholesterol, glucose, predicted FEV1, weight, body mass index, waist hip ratio, number of rooms and units of alcohol consumed per week (Table 1). Regression coefficients are given for one standard deviation (15 units) of parental IQ. There were significant relationships between parental IQ and height and its components, leg length and trunk length, whereby greater parental IQ was associated with taller offspring. There was a significant inverse relationship between parental IQ and number of cigarettes smoked. Parental IQ was significantly associated with all the measures of education, offspring social class and offspring deprivation category. There were no significant relationships found with the discrete variables.

Since number of cigarettes smoked in offspring was significantly related to parental IQ, models were also constructed using parental social class and deprivation category (Table 2). Parental IQ was inversely related to number of cigarettes smoked by offspring. When social class was added to the model, parental IQ remained 
Table 1. Characteristics of offspring related to parental IQ

\begin{tabular}{|c|c|c|c|}
\hline & $N$ & Mean (SD) & $\begin{array}{l}\text { Regression coefficients per } 1 \mathrm{SD} \\
\text { IQ and } 95 \% \text { confidence intervals }\end{array}$ \\
\hline Systolic blood pressure (mmHg) & 283 & $128(16 \cdot 6)$ & $-0 \cdot 18(-2 \cdot 46$ to $2 \cdot 1)$ \\
\hline Diastolic blood pressure $(\mathrm{mmHg})$ & 283 & $76(11 \cdot 1)$ & $0.05(-1.53$ to 1.62$)$ \\
\hline Cholesterol $(\mathrm{mmol} / \mathrm{l})$ & 277 & $5 \cdot 3(0 \cdot 9)$ & $-0.07(-0.21$ to 0.06$)$ \\
\hline Glucose $(\mathrm{mmol} / \mathrm{l})$ & 279 & $5.4(1.9)$ & $0.03(-0.21$ to 0.27$)$ \\
\hline$\%$ predicted FEV1 & 280 & $96 \cdot 6(14 \cdot 7)$ & $0.47(-1.65$ to $1 \cdot 1)$ \\
\hline Height (mm) & 286 & $1 \cdot 67(0 \cdot 1)$ & $17 \cdot 39(3 \cdot 54$ to $31 \cdot 23)$ \\
\hline Leg length (mm) & 286 & $0 \cdot 77(0.06)$ & $10 \cdot 17(1.77$ to $18 \cdot 57)$ \\
\hline Trunk length (mm) & 286 & $0.89(0.05)$ & $7 \cdot 25(0.66$ to $13 \cdot 84)$ \\
\hline Weight $(\mathrm{kg})$ & 285 & $72 \cdot 1(15 \cdot 5)$ & $0.06(-2.06$ to $2 \cdot 19)$ \\
\hline Body mass index $\left(\mathrm{kg} / \mathrm{m}^{2}\right)$ & 285 & $25 \cdot 9(4 \cdot 8)$ & $-0.53(-1.2$ to $0 \cdot 14)$ \\
\hline Waist hip ratio & 281 & $0.84(0.09)$ & $-0.004(-0.02$ to 0.01$)$ \\
\hline Number of rooms & 286 & $5 \cdot 4(1 \cdot 7)$ & $0 \cdot 2(-0.04$ to $0 \cdot 44)$ \\
\hline Alcohol (units/week) & 286 & $12 \cdot 4(14 \cdot 5)$ & $1 \cdot 13(-0.71$ to $2 \cdot 96)$ \\
\hline Cigarettes per day & 286 & $16 \cdot 9^{\mathrm{a}}(9 \cdot 5)$ & $-1.92(-3.42$ to -0.42$)$ \\
\hline Years of education & 285 & $12 \cdot 0(2 \cdot 5)$ & $0.76(0.41$ to 1.11$)$ \\
\hline Number of Standard Grades/O levels & 286 & $5 \cdot 0^{\mathrm{b}}(2 \cdot 4)$ & $0.85(0.42$ to 1.27$)$ \\
\hline Number of Highers/A levels & 286 & $3 \cdot 6^{\mathrm{b}}(1 \cdot 8)$ & $0.53(0 \cdot 25$ to $0 \cdot 81)$ \\
\hline Highest level of education & 284 & $3^{\mathrm{c}}$ (school) & $-0 \cdot 18(-0.26$ to $-0 \cdot 1)$ \\
\hline Social class & 286 & $\mathrm{II}^{\mathrm{c}}$ & $-0.21(-0.39$ to -0.02$)$ \\
\hline \multirow[t]{2}{*}{ Deprivation category } & 286 & $3^{\mathrm{c}}$ & $-0.22(-0.41$ to -0.03$)$ \\
\hline & & $\%$ yes & $\begin{array}{l}\text { Odds ratio and } 95 \% \\
\text { confidence interval }\end{array}$ \\
\hline Smoking & 286 & $59 \cdot 1 \%$ & $0.98(0.96$ to 1.001$)$ \\
\hline Alcohol consumption & 286 & $79 \cdot 4 \%$ & $1.01(0.98$ to 1.03$)$ \\
\hline Married & 286 & $78 \cdot 3 \%$ & $1.01(0.99$ to 1.03$)$ \\
\hline Owner occupier & 286 & $82 \cdot 9 \%$ & $1.02(0.99$ to 1.06$)$ \\
\hline Car user & 285 & $85 \cdot 7 \%$ & $1.03(0.999$ to 1.07$)$ \\
\hline Exerciser & 286 & $72 \cdot 7 \%$ & $1.0(0.99$ to 1.02$)$ \\
\hline
\end{tabular}

${ }^{\mathrm{a} C}$ Current and former smokers.

${ }^{\mathrm{b}}$ For those gaining at least one.

${ }^{\mathrm{c}}$ Mode.

virtually unaltered and social class was not significant. A similar effect was seen with deprivation category. Parental social class and deprivation category separately were not associated with number of cigarettes smoked by the offspring. Parental smoking was not associated with amount smoked by offspring (not shown).

Parental IQ was positively related to total height, leg length and trunk length of offspring (Table 3). Adding parental deprivation category to the models attenuated the effect of IQ more strongly than adding social class, and social class and deprivation category were not statistically significant in these models, although parental IQ remained significant (except for trunk length). Models of offspring height 
Table 2. Models with number of cigarettes smoked per day related to parental IQ, social class and deprivation category

\begin{tabular}{lccc}
\hline & \multicolumn{3}{c}{$\begin{array}{c}\text { Regression coefficients and 95\% } \\
\text { confidence intervals for parental measures }\end{array}$} \\
\cline { 2 - 4 } Model with: & IQ & Social class & Deprivation category \\
\hline IQ & $-2.02(-3.52$ to -0.52$)$ & \\
IQ \& social class & $-1.83(-3.41$ to -0.25$)$ & $0.45(-0.67$ to 1.58$)$ & $0.16(-0.98$ to 1.29$)$ \\
$\begin{array}{l}\text { IQ \& deprivation } \\
\quad \text { category }\end{array}$ & $-1.96(-3.53$ to -0.39$)$ & $0.84(-0.24$ to 1.92$)$ & $0.54(-0.56$ to 1.65$)$ \\
$\begin{array}{l}\text { Social class } \\
\text { Deprivation category }\end{array}$ & & & \\
\hline
\end{tabular}

(and constituents) with parental IQ and parental height showed parental height to be significant and parental IQ not significant.

Higher parental IQ was associated with offspring being in higher social classes (Table 4). Adding parental social class or parental deprivation category to the model resulted in IQ being non-significant. The model with IQ, parental social class and parental deprivation category resulted in only parental social class being significant. Higher parental IQ was associated with offspring being in more affluent deprivation categories. When parental deprivation category was added, it was highly significant and IQ was not significant.

Parental IQ was positively associated with years of education in offspring (Table 5). Adding parental social class to the model resulted in both IQ and social class being significant and similarly adding deprivation category to the model resulted in both IQ and deprivation being significant. With IQ, social class and deprivation in the model, IQ and social class were significant. The addition of social class and deprivation category had a small effect on the size of the IQ coefficient. Age was significant in models of parental IQ and number of Standard Grades or O levels obtained and number of Highers or A levels obtained. Parental IQ was positively associated with the number of Standard Grades or O levels obtained and was attenuated when social class and deprivation category were added. Parental IQ was positively associated with the number of Highers or A levels achieved. Adjustment for parental social class had a small effect but not adjustment for parental deprivation category. Higher parental IQ was associated with a higher level of education achieved. Social class, but not deprivation category, was significant when included in the models.

There were no significant interaction terms between parental IQ and parental social class or deprivation category.

When the analyses were repeated for mothers and fathers separately, for most of the variables the results were the same as when the parental data were considered together (not shown). However, there were significant relationships between paternal, but not maternal IQ, and body mass index, cigarettes smoked per day, height, leg 


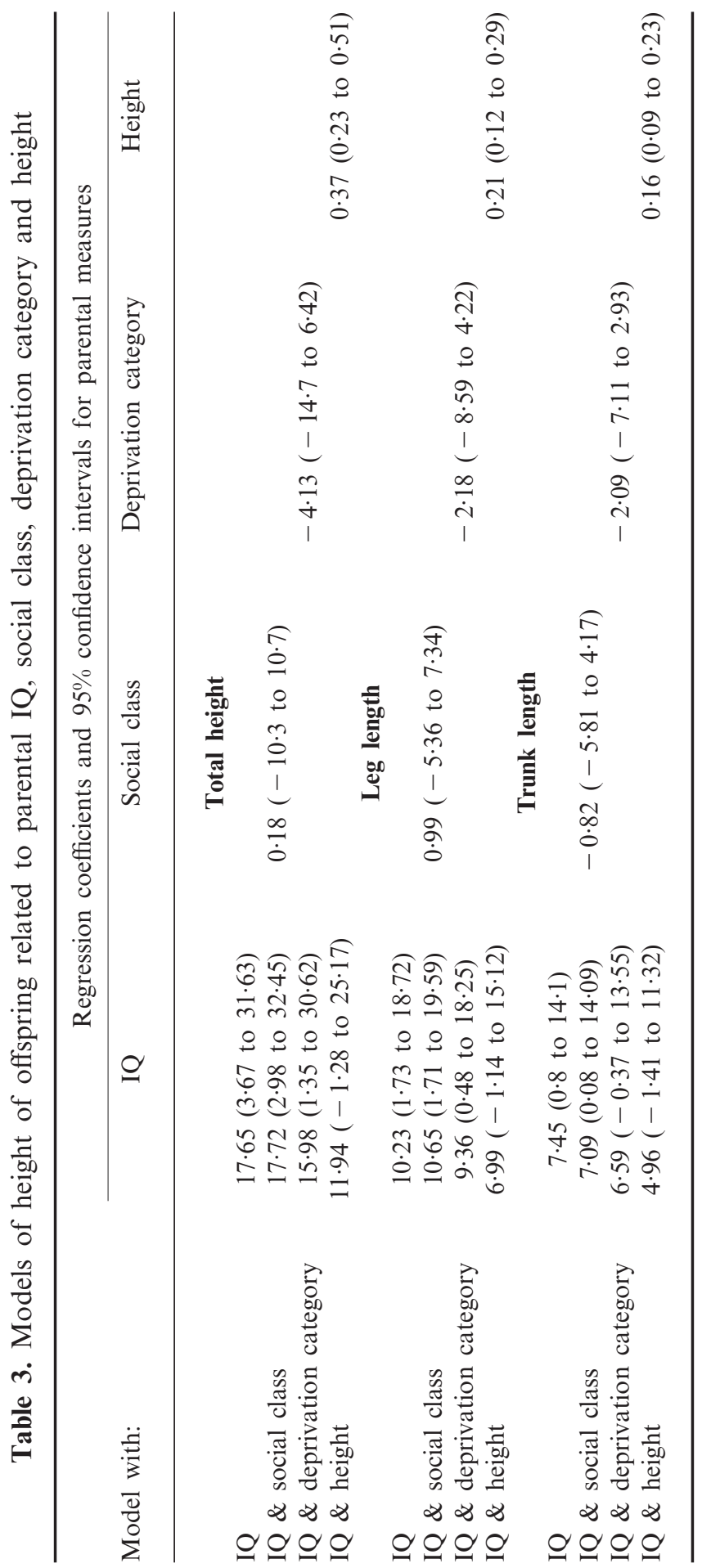




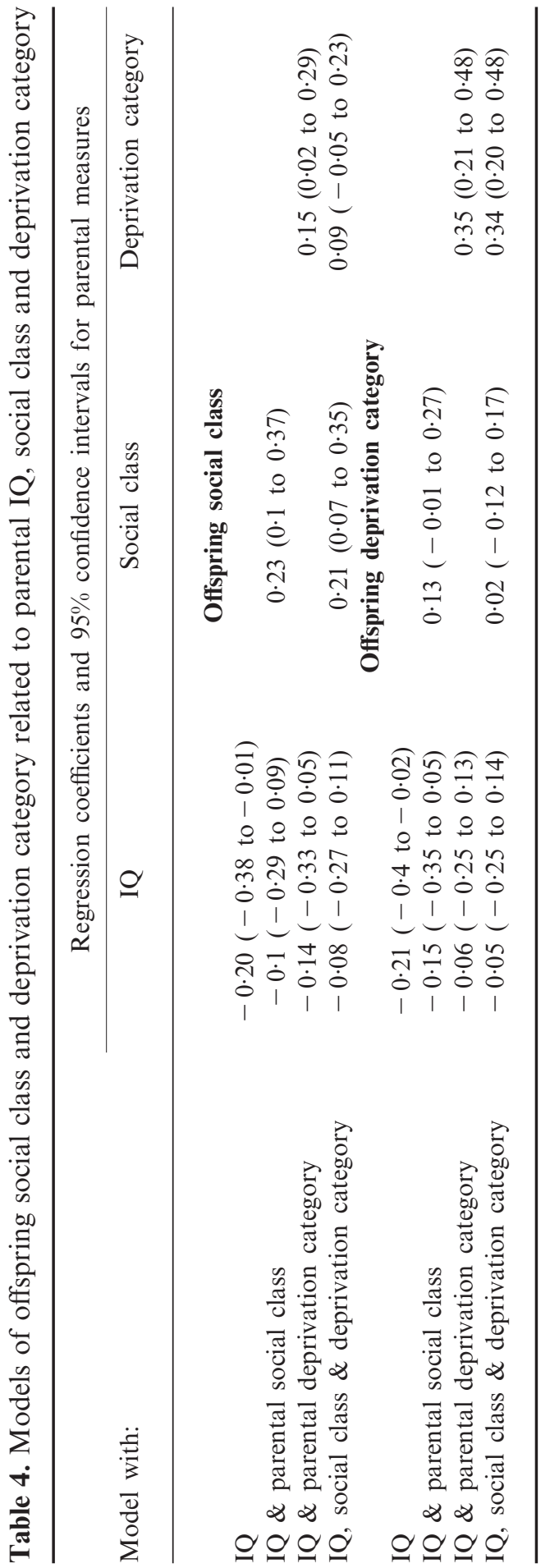


C. L. Hart et al.

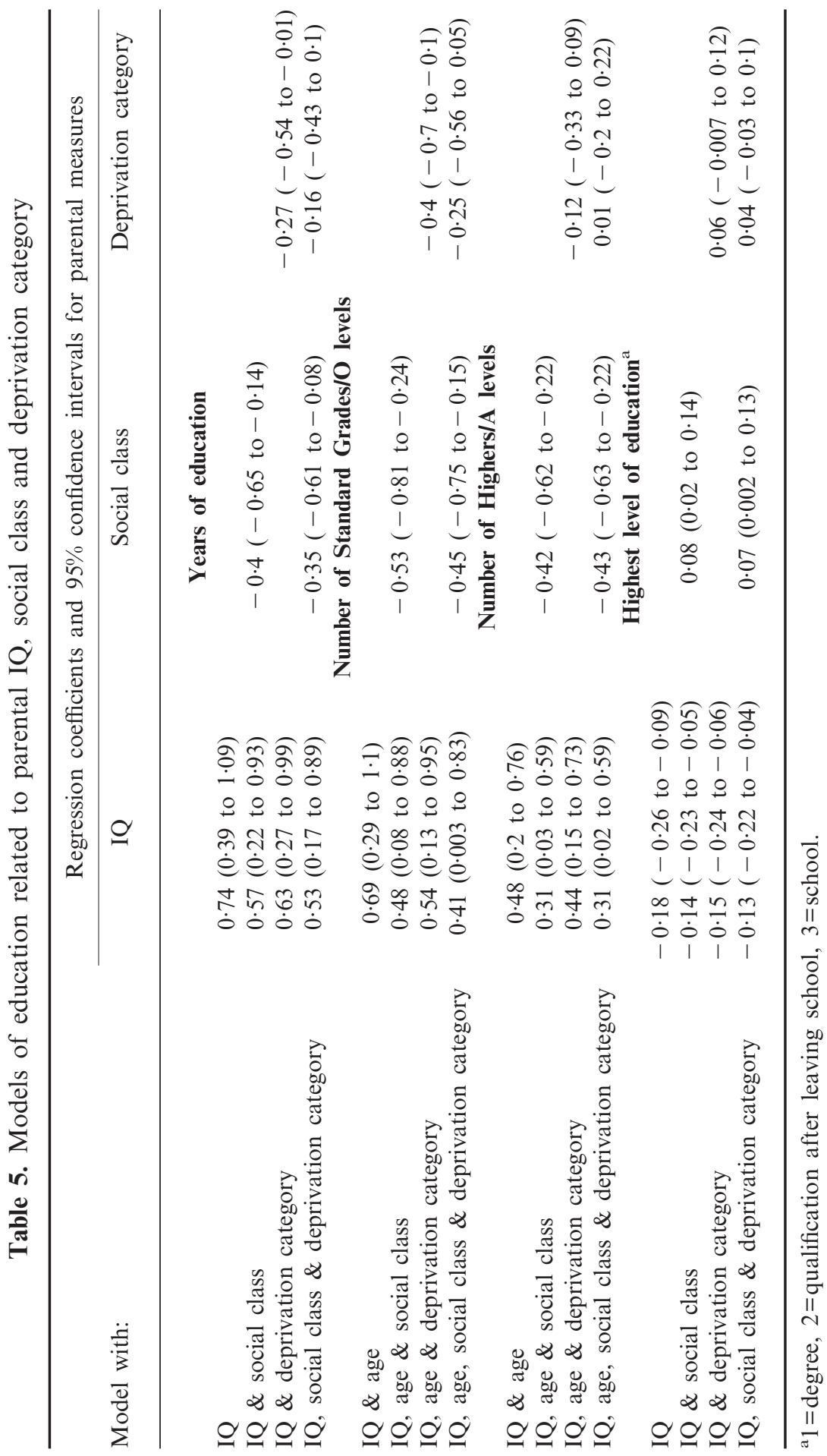


length and trunk length in offspring, and there were significant relationships between maternal, but not paternal IQ, and offspring social class and car user.

Structural equation modelling examined the hypothesis that parental IQ, mediated via mid-life social factors, influenced health and social characteristics of offspring when they became adults. Table 6 gives the correlation coefficients of the parental and offspring variables used. The Wald test was used to indicate hypothesized paths in the model that were non-significant. All paths shown in the model have significant $(p<0.05)$ parameters (Fig. 1). The fit statistics of the model are all good: the average of the off-diagonal absolute standardized residuals $=0.034$ (values below 0.04 indicate good fit); chi squared for the model $=10.7(\mathrm{df}=12, p=0.55)$ (non-significant values indicate good fit). Both of these tests indicate that the residual covariance among the measured variables was low after the model's paths were taken into account. The Bentler-Bonett (normed and non-normed) and comparative fit indices were $0 \cdot 92,1 \cdot 0$ and $1 \cdot 0$, respectively (range from 0 to 1 ; values above 0.9 indicate good fit). These are goodness-of-fit indices which reflect how well the model fits the variables' covariance matrix. The model shows that parental IQ at age 11 had significant associations with parental social class and deprivation at mid-life. Parental IQ was associated with offspring education directly and mediated via parental social class. Offspring education was associated with offspring smoking and social class. There were direct associations between parental and offspring social class, and between parental and offspring deprivation.

\section{Discussion}

This study has shown links between childhood IQ of parents and characteristics of their offspring. As far as the authors know, this study is unique, although an American study related mental ability in mothers to characteristics such as low birth weight and temperament in their babies (Herrnstein \& Murray, 1994). The offspring in that study were still young though. In the current study, amount smoked by offspring, their adult height, social class and deprivation category of residence, and their educational achievements were associated with their parent's IQ. Several of the variables tested were not associated with parental IQ. These included blood pressure, lung function, weight and alcohol consumption.

This study found that offspring of less intelligent parents smoked more cigarettes. In contrast, parental social class and deprivation category were not related to amount smoked by offspring. Parental smoking was not related to offspring smoking in this study. However, an analysis of nearly all of the family study data (i.e. not only those with 1921-born parents) did find associations between parental and offspring smoking (Upton et al., 2004). The structural equation model showed links to offspring smoking via offspring education. These findings have implications for health education. When the smoking habits of the offspring were recorded in 1996, the deleterious effects of smoking were well known and had been known at the time of smoking initiation for most of this cohort. Perhaps the offspring of the more intelligent heeded the warnings and did not smoke, gave up or smoked fewer cigarettes. Smoking cessation was associated with higher IQ in the whole Midspan-SMS1932 cohort (Taylor et al., 2003). Another study which found a parent IQ-child health association showed the 
C. L. Hart et al.

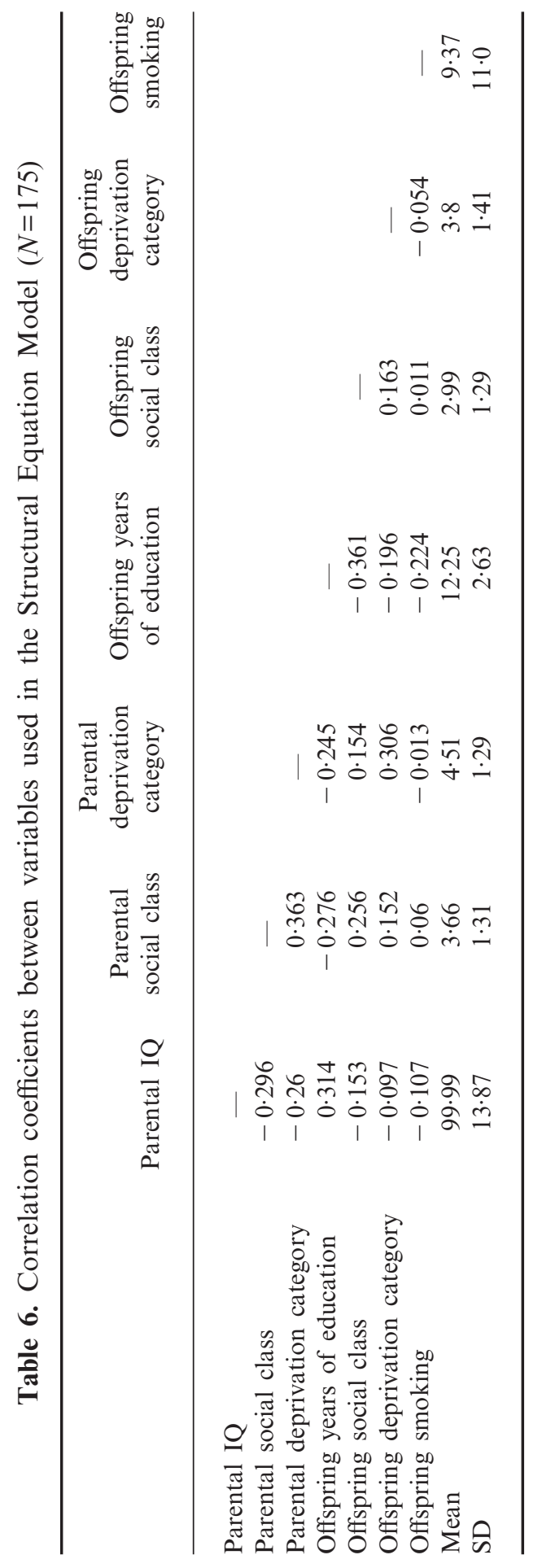




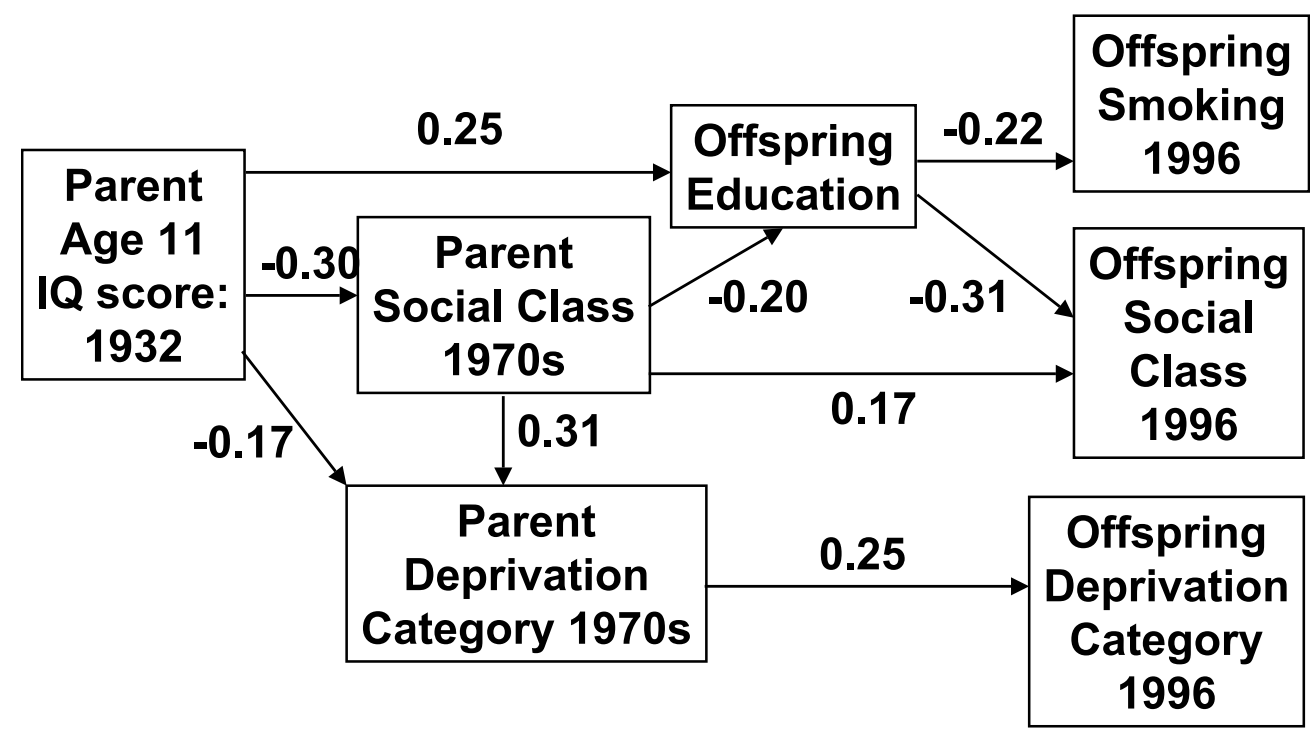

Fig. 1. IQ, social attainment and health: parents and offspring. Scottish Mental Survey 1932 linked with Midspan. $N=175$ parent-offspring pairs; AO-DSR $=0 \cdot 034$; chi squared $=10 \cdot 7(\mathrm{df}=12, p=0.55)$; Bentler-Bonett (NFI \& NNFI) and comparative $\mathrm{FI}=0 \cdot 92,1 \cdot 0,1 \cdot 0$, respectively.

IQ of mothers, as measured by the National Adult Reading Test (NART), to be related to their children's diabetes control (Ross et al., 2001).

Parental IQ was related to offspring height and its components. The components of height - leg length and trunk length - are thought to be influenced by different early life factors, with leg length being more closely related to early socioeconomic circumstances and diet, and trunk length being more closely related to serious childhood illness (Wadsworth et al., 2002a). It was therefore possible that IQ would only be related to one particular component of height. A study of height, leg length and trunk length in the British Women's Heart and Health Study found that height and its components were all positively associated with breast cancer (Lawlor et al., 2003). The IQ effect on offspring height survived adjustment for the social factors but not adjustment for parental height. Height is considered a proxy measure for socioeconomic circumstances in childhood (Davey Smith et al., 2000), but here parental IQ was found to be a stronger indicator of offspring height than the social factors. Parental height has close genetic links with offspring height, which can explain why IQ was no longer significant in the model adjusted for parental height.

Although parental IQ was related to offspring social class, parental social class was more important than parental IQ. Similar effects were seen for offspring deprivation category. This was also demonstrated by the direct associations between parental and offspring social class and parental and offspring deprivation category in the structural equation model.

Parental IQ was strongly associated with the educational variables which encompassed duration of education and achievements in public examinations. 
Adoption and twin studies have shown that parental IQ is closely related to IQ of offspring (Turkheimer, 1991; Loehlin et al., 1994; Neisser et al., 1996; Wadsworth et al., 2002b), and since individual IQ is related to educational achievement (Neisser et al., 1996), the relationship between parental IQ and education would be expected. Parental social factors were also related to offspring education variables and acted in addition to parental IQ.

Lower mental ability is associated with higher blood pressure in middle-aged and older adults (Starr, 1999; Starr et al., 2004). The causal direction of this association remains unclear since lowering blood pressure has been shown to benefit cognition, and this only minimally, in only three clinical trials of any length (Starr et al., 1996; Forette et al., 1998; Tzourio et al., 2003) whilst not having any effects in three others (SHEP Cooperative Research Group, 1991; Prince et al., 1996; Lithell et al., 2003). Like IQ, both systolic and diastolic blood pressure are highly heritable with genetic factors accounting for between 35 and $70 \%$, depending on population, with this contribution being stable across time (Vinck et al., 2001; Sneider et al., 2003). This finding of a lack of any significant association between parental IQ and offspring blood pressure makes linkage of these heritabilities (e.g. through shared genes) even less likely. If parental IQ is to influence offspring's blood pressure, it is likely to act through environmental and lifestyle pathways, but the effect sizes for each link in any causal chain (e.g. parental IQ-offspring social class-offspring blood pressure) are not large enough for any association to be observed in this sample. This is helpful in focusing investigation of the causal links between IQ and blood pressure: it is suggested they must be largely confined to IQ-related environmental and lifestyle factors of the individual with a possible minor reverse effect of blood pressure on IQ in older adults.

The study had some limitations. Firstly, not all of the 1921-born older generation were matched to a mental ability score on the SMS1932 (Hart et al., 2003a). However, those not matched had similar characteristics to those matched. There were 244 1921-born parents whose offspring took part in the family study. Of these, $192(79 \%)$ had a mental ability score recorded. Secondly, not all the offspring took part in the second part of the family study (Upton et al., 2000). Some were not asked to take part because they were no longer in the area, and some who were invited did not attend. A third limitation was the inability to have an IQ measure for both parents, but that was due to the data on mental ability being restricted to those parents born in 1921 only.

To summarize, this unique study has shown that parental IQ is related to smoking, height, social class, deprivation category and educational achievements of their offspring. The reported associations confound genetic and environmental influences as they are based on biological families. A behaviour genetic design would be required to disentangle these two factors. A more informative study design would include the same information on a sample of adoptive parents and their adopted children. Nevertheless, the study has enriched the understanding of cross-generational health and social associations by using an individual variable, parental IQ, in addition to the more commonly studied variables social class and deprivation. Parental IQ was a strong associate of offspring's educational qualifications, but offspring social class and deprivation category were more affected by parental social class and deprivation category. The parental IQ-smoking finding may aid the targeting of health education on smoking prevention. 


\section{Acknowledgments}

The Scottish Council for Research in Education is thanked for making the data from the Scottish Mental Survey 1932 available to the authors. Victor Hawthorne was responsible for the original Midspan studies. Alex McConnachie provided the offspring data. Geoff Der is thanked for statistical advice. Funding was provided by the Chief Scientist's Office of the Scottish Executive. IJD is the recipient of a Royal Society-Wolfson Research Merit Award. LJW holds a Wellcome Trust Career Development Award.

\section{References}

Barker, D. (1994) Mothers, Babies, and Disease in Later Life. BMJ Publishing Group, London. Bentler, P. (1995) EQS Structural Equations Program Manual. Multivariate Software Inc, Encino, CA.

Carstairs, V. \& Morris, R. (1991) Deprivation and Health in Scotland. Aberdeen University Press, Aberdeen.

Davey Smith, G., Hart, C., Hole, D., MacKinnon, P., Gillis, C., Watt, G., Blane, D. \& Hawthorne, V. (1998a) Education and occupational social class: which is the more important indicator of mortality risk? Journal of Epidemiology and Community Health 52, 153-160.

Davey Smith, G., Hart, C. L., Blane, D. \& Hole, D. (1998b) Adverse socioeconomic conditions in childhood and cause specific adult mortality: prospective observational study. British Medical Journal 316, 1631-1635.

Davey Smith, G., Hart, C. L., Upton, M., Hole, D., Gillis, C., Watt, G. C. M. \& Hawthorne, V. (2000) Height and risk of death among men and women: aetiological implications of associations with cardiorespiratory disease and cancer mortality. Journal of Epidemiology and Community Health 54, 97-103.

Elo, I. T. \& Preston, S. H. (1992) Effects of early-life conditions on adult mortality: a review. Population Index 58, 186-212.

Forette, F., Seux, M., Staessen, J., Thijs, L., Birkenhager, W., Babarskiene, M. et al. (1998) Prevention of dementia in randomised double-blind placebo-controlled Systolic Hypertension in Europe (Syst-Eur) trial. Lancet 352, 1347-1351.

General Register Office (1966) Classification of Occupations 1966. HMSO, London.

Gunnell, D., Whitley, E., Upton, M., McConnachie, A., Davey Smith, G. \& Watt, G. (2003) Associations of height, leg length, and lung function with cardiovascular risk factors in the Midspan Family Study. Journal of Epidemiology and Community Health 57, 141-146.

Hart, C. L., Deary, I. J., Taylor, M. D., MacKinnon, P. L., Davey Smith, G., Whalley, L. J., Wilson, V., Hole, D. J. \& Starr, J. M. (2003a) The Scottish Mental Survey 1932 linked to the Midspan studies: a prospective investigation of childhood intelligence and future health. Public Health 117, 187-195.

Hart, C. L., Taylor, M. D., Davey Smith, G., Whalley, L. J., Starr, J. M., Hole, D. J., Wilson, V. \& Deary, I. J. (2003b) Childhood IQ, social class, deprivation and their relationships with mortality and morbidity risk in later life: prospective observational study linking the Scottish Mental Survey 1932 and the Midspan studies. Psychosomatic Medicine 65, 877-883.

Hawthorne, V. M., Watt, G. C. M., Hart, C. L., Hole, D. J., Davey Smith, G. \& Gillis, C. R. (1995) Cardiorespiratory disease in men and women in urban Scotland: baseline characteristics of the Renfrew/Paisley (Midspan) Study population. Scottish Medical Journal 40, 102-107. 
Herrnstein, R. \& Murray, C. (1994) The Bell Curve: Intelligence and Class Structure in American Life. Free Press, New York.

Kuh, D., Hardy, R., Langenberg, C., Richards, M. \& Wadsworth, M. (2002). Mortality in adults aged 26-54 years related to socioeconomic conditions in childhood and adulthood: post war birth cohort study. British Medical Journal 325, 1076-1080.

Lawlor, D. A., Okasha, M., Gunnell, D., Davey Smith, G. \& Ebrahim, S. (2003) Associations of adult measures of childhood growth with breast cancer: findings from the British Women's Heart and Health Study. British Journal of Cancer 89, 81-87.

Lithell, H., Hansson, L., Skoog, I., Elmfeldt, D., Hofman, A., Olofsson, B., Trenkwalder, P. \& Zanchetti, A. (2003) The study on cognition and prognosis in the elderly (SCOPE): principal results of a randomized double-blind intervention trial. Journal of Hypertension 21, 875-886.

Loehlin, J., Horn, J. \& Willerman, L. (1994) Differential inheritance of mental abilities in the Texas Adoption Project. Intelligence 19, 325-336.

Neisser, U., Boodoo, G., Bouchard, T., Boykin, A., Brody, N., Ceci, S., Halpern, D., Loehlin, J., Perloff, R., Sternberg, R. \& Urbiba, S. (1996) Intelligence: knowns and unknowns. American Psychologist 51, 77-101.

Poulton, R., Caspi, A., Milne, B., Thomson, W., Taylor, A., Sears, M. \& Moffitt, T. (2002) Association between children's experience of socioeconomic disadvantage and adult health: a life-course study. Lancet 360, 1640-1645.

Prince, M., Bird, A., Blizard, R. \& Mann, A. (1996) Is the cognitive function of older patients affected by antihypertensive treatment? Results from 54 months of the Medical Research Council's treatment trial of hypertension in older adults. British Medical Journal 312, 801-805.

Ross, L. A., Frier, B. M., Kelnar, C. J. \& Deary, I. J. (2001) Child and parental mental ability and glycaemic control in children with type 1 diabetes. Diabetic Medicine 18, 364-369.

Scottish Council for Research in Education (1933) The Intelligence of Scottish Children: A National Survey of an Age-Group. University of London Press, London.

SHEP Cooperative Research Group (1991) Prevention of stroke by antihypertensive drug treatment in older persons with isolated systolic hypertension. Final results of the Systolic Hypertension in the Elderly Program (SHEP). Journal of the American Medical Association 265, 3255-3264.

Snieder, H., Harshfield, G. \& Treiber, F. (2003) Heritability of blood pressure and hemodynamics in African- and European-American youth. Hypertension 41, 1196-1201.

Starr, J., Taylor, M., Hart, C., Davey Smith, G., Whalley, L., Hole, D., Wilson, V. \& Deary, I. J. (2004) Childhood mental ability and blood pressure at midlife: linking the Scottish Mental Survey 1932 and the Midspan studies. Journal of Hypertension 22, 893-897.

Starr, J. M. (1999) Blood pressure and cognitive decline in the elderly. Current Opinion in Nephrology \& Hypertension 8, 347-351.

Starr, J. M., Whalley, L. J. \& Deary, I. J. (1996) The effects of antihypertensive treatment on cognitive function: results from the HOPE study. Journal of the American Geriatrics Society 44, 411-415.

Taylor, M. D., Hart, C. L., Davey Smith, G., Starr, J. M., Hole, D. J., Whalley, L. J., Wilson, V. \& Deary, I. J. (2003) Childhood mental ability and smoking cessation in adulthood: prospective observational study linking the Scottish Mental Survey 1932 and the Midspan studies. Journal of Epidemiology and Community Health 57, 464- 465.

Turkheimer, E. (1991) Individual and group-differences in adoption studies of IQ. Psychological Bulletin 110, 392-405.

Tzourio, C., Anderson, C., Chapman, N., Woodward, M., Neal, B., MacMahon, M. \& Chalmers, J. (2003) Effects of blood pressure lowering with perindopril and indapamide therapy on 
dementia and cognitive decline in patients with cerebrovascular disease. Archives of Internal Medicine 163, 1069-1075.

Upton, M., Davey Smith, G., McConnachie, A., Hart, C. \& Watt, G. (2004) Maternal and personal cigarette smoking synergize to increase airflow limitation in adults. American Journal of Respiratory and Critical Care Medicine 169, 479-487.

Upton, M., McConnachie, A., McSharry, C., Hart, C., Davey Smith, G., Gillis, C. \& Watt, G. (2000) Intergenerational 20 year trends in the prevalence of asthma and hay fever in adults: the Midspan family study surveys of parents and offspring. British Medical Journal 321, $88-92$.

Vinck, W., Fagard, R., Loos, R. \& Vlietinck, R. (2001) The impact of genetic and environmental influences on blood pressure variance across age-groups. Journal of Hypertension 19, 1007-1013.

Wadsworth, M., Hardy, R., Paul, A., Marshall, S. \& Cole, T. (2002a) Leg and trunk length at 43 years in relation to childhood health, diet and family circumstances; evidence from the 1946 national birth cohort. International Journal of Epidemiology 31, 383-390.

Wadsworth, S. J., Corley, R. P., Hewitt, J. K., Plomin, R. \& DeFries, J. C. (2002b) Parent-offspring resemblance for reading performance at 7,12 and 16 years of age in the Colorado Adoption Project. Journal of Child Psychology and Psychiatry and Allied disciplines 43, 769-774.

Whalley, L. J. \& Deary, I. J. (2001) Longitudinal cohort study of childhood IQ and survival up to age 76. British Medical Journal 322, 819-822. 